\title{
Density Functional Theory Calculations of the Oxidative Dehydrogenation of Propane on the (010) Surface of $\mathrm{V}_{2} \mathrm{O}_{5}^{\dagger}$
}

\author{
François Gilardoni, ${ }^{\ddagger}$ Alexis T. Bell, ${ }^{*,+, \perp}$ Arup Chakraborty, ${ }^{\S, l, \perp}$ and Pascal Boulet ${ }^{\#}$ \\ Chemical and Materials Sciences Divisions, Lawrence Berkeley National Laboratory, Departments of \\ Chemistry and Chemical Engineering, University of California, Berkeley, California 94720-1462, and \\ Department of Physical Chemistry, University of Geneva, 30 Quai Ernest-Ansermet, \\ CH-1211 Geneve 4, Switzerland
}

Received: May 11, 2000; In Final Form: September 11, 2000

\begin{abstract}
Density functional theory and the calculations of oxygen nucleophilicity have been applied to an analysis of the oxidative dehydrogenation $(\mathrm{ODH})$ of propane on the $(010)$ surface of $\mathrm{V}_{2} \mathrm{O}_{5}$. These calculations show that the energetically preferred initial step is the dissociative adsorption of propane to form $i$-propoxide and hydroxyl species. Two $\mathrm{V}=\mathrm{O}$ groups $[\mathrm{O}(1)]$ bonded by a $\mathrm{V}-\mathrm{O}-\mathrm{V}$ bridge are required. One of the vanadyl groups attacks the $\beta$-C atom of propane and is converted to a $\mathrm{V}-\mathrm{OCH}_{2}\left(\mathrm{CH}_{3}\right)_{2}$ species, whereas the other vanadyl group is converted into a $\mathrm{V}-\mathrm{OH}$ group. The activation barrier for this process is $9.4 \mathrm{kcal} / \mathrm{mol}$. Dissociative adsorption to form an $n$-propoxide can also occur, but the activation barrier for this process is $14.5 \mathrm{kcal} / \mathrm{mol}$. Propene and water are formed via a concerted process in which an $\mathrm{H}$ atom of one of the methyl groups of $i$-propoxide reacts with an $\mathrm{O}(3) \mathrm{H}$ group. Exploration of alternative pathways for this step reveals that neither $\mathrm{O}(1,2,3), \mathrm{O}(1) \mathrm{H}$, nor $\mathrm{O}(2) \mathrm{H}$ are sufficiently reactive. These findings are in good qualitative agreement with experimental observations concerning the mechanism and kinetics of propane ODH.
\end{abstract}

\section{Introduction}

Selective dehydrogenation of alkanes remains a formidable challenge for the wider use of alkanes as feedstock. Thermal dehydrogenation of light alkanes to olefins is thermodynamically favorable at high temperatures, but often leads to high yields of coke and smaller hydrocarbons. Oxidative dehydrogenation $(\mathrm{ODH})$ of alkanes is thermodynamically favored at much lower temperatures, but it requires a selective catalyst in order to avoid complete oxidation to $\mathrm{CO}$ and $\mathrm{CO}_{2}$, although the presence of $\mathrm{O}_{2}$ inhibits the carbon deposition prevalent in non oxidative routes. Many of the best alkane ODH catalysts contain either dispersed vanadia or particles of $\mathrm{V}_{2} \mathrm{O}_{5} \cdot{ }^{1-8}$ Detailed studies of propane $\mathrm{ODH}$ have shown that the highest turnover frequencies are obtained with catalysts having a high proportion of polyvanadate species. ${ }^{4,5,8}$ It has also been demonstrated that the turnover frequencies for polyvanadate species and $\mathrm{V}$ atoms located at the surface of $\mathrm{V}_{2} \mathrm{O}_{5}$ are comparable. Isotopic labeling studies have shown, in addition, that lattice oxygen is involved and that $\mathrm{ODH}$ proceeds via a redox mechanism. ${ }^{8-11}$ What remains unclear, though, is which of the three different types of oxygen present at the surface of $\mathrm{V}_{2} \mathrm{O}_{5}$ are involved in the mechanism of propane $\mathrm{ODH}$, and evidence has been presented for all three forms. Experimental studies by Oyama and coworkers $^{12}$ have proposed that singly coordinated vanadyl oxygen, $\mathrm{O}(1)$, is the active center for $\mathrm{SiO}_{2}$-supported $\mathrm{V}_{2} \mathrm{O}_{5}$, whereas Eon et al. ${ }^{13}$ have proposed that the active site on $\gamma-\mathrm{Al}_{2} \mathrm{O}_{3}$-supported $\mathrm{V}_{2} \mathrm{O}_{5}$ are 2 -fold coordinated, bridging

\footnotetext{
Dedicated to the 60th birthday of Professor Jacques Weber.

* Author to whom correspondence should be addressed.

$\doteqdot$ Chemical Sciences Division, Lawrence Berkeley National Laboratory.

$\S$ Materials Sciences Division, Lawrence Berkeley National Laboratory.

II Department of Chemistry, University of California.

${ }^{\perp}$ Department of Chemical Engineering, University of California.

\# University of Geneva.
}

oxygen atoms, $\mathrm{O}(2)$. Quantum chemical calculations of the binding strength of $\mathrm{H}$ atoms with the surface of $\mathrm{V}_{2} \mathrm{O}_{5}$ have been used in an attempt to ascertain the relative reactivity of different forms of oxygen. Ramirez et al. ${ }^{14}$ have shown by SCF HartreeFock calculations that removal of $\mathrm{O}(3)$ leads to the most stable vacancy, suggesting that 3-fold coordinated, bridging oxygen atoms, $\mathrm{O}(3)$, are the most reactive. By contrast, Hartree-Fock and DFT calculations with small $\mathrm{VO}_{x}$ clusters conducted by Witko and co-workers ${ }^{15-18}$ suggest that $\mathrm{H}$ atoms bond preferentially with $\mathrm{O}(2)$ sites, but more recent DFT calculations with large embedded clusters conducted by Hermann et al. ${ }^{19}$ conclude that $\mathrm{H}$ atoms are bound most strongly to $\mathrm{O}(1)$ sites. The role of surface oxygen atoms in the mechanism and kinetics of propane $\mathrm{ODH}$ has been discussed recently by Chen et al. ${ }^{8,11}$ It is proposed that propene is formed by dissociative adsorption of propane, a process requiring two surface oxygen atoms, which results in the formation of propoxide and hydroxyl groups. This process is then followed by the release of a second hydrogen atom to yet another surface oxygen atom.

The objective of the present study is to elucidate the reaction pathway and the energetics for the ODH of propane on the surface of $\mathrm{V}_{2} \mathrm{O}_{5}$. Density functional theory (DFT) has been used for this purpose. ${ }^{20,21}$ Semiempirical methods and Fukui functions have been used to sample the potential energy surfaces. The information gained from Fukui functions has been used to identify the most probable active sites. ${ }^{22}$

\section{Computational Details}

The (010) surface of $\mathrm{V}_{2} \mathrm{O}_{5}$ is represented by a finite cluster. This approach is valid when the adsorbate perturbs the substrate only in the immediate vicinity of the site at which the adsorbate is bound. ${ }^{15,23-27}$ Assuming these conditions to prevail, a $\mathrm{V}_{2} \mathrm{O}_{9}$ cluster with $C_{s}$ symmetry was used to model the surface for the first step of propane $\mathrm{ODH}$. The $\mathrm{V}$ atoms adjacent to the 
cluster were substituted by $\mathrm{H}$ atoms. The positions of the six coplanar $\mathrm{O}-\mathrm{H}$ groups bonded to the vanadium atoms in $\mathrm{V}_{2} \mathrm{O}_{9}$ were kept fixed during the optimizations of the cluster geometry, such that the $\mathrm{O}$ atoms were located at their crystallographic positions in $\mathrm{V}_{2} \mathrm{O}_{5}$ and the $\mathrm{O}-\mathrm{H}$ bond distance was held at 1.80 $\AA$. Witko et al. ${ }^{15}$ have shown that the electronic properties of the oxygen atoms in the interior of the cluster are not changed if the substrate cluster size is increased beyond $\mathrm{V}_{2} \mathrm{O}_{9}$ and that saturation of the peripheral oxygen bonds by hydrogen has only a minor influence on the oxygen sites. The size of the cluster was enlarged to $\mathrm{V}_{4} \mathrm{O}_{14}$ to model the second step of ODH. The structure of this cluster was based on that of bulk $\mathrm{V}_{2} \mathrm{O}_{5}$ which forms an orthorhombic (space group Pmmn) layer crystal with lattice parameters $a=11.51 \AA, b=4.37 \AA$, and $c=3.56 \AA$. As for the $\mathrm{V}_{2} \mathrm{O}_{9}$ cluster, peripheral oxygen atoms were saturated by terminal $\mathrm{H}$ atoms. Only $\mathrm{O}(1), \mathrm{O}(2), \mathrm{O}(3)$ and their first neighbors belonging to the (010) surface of $\mathrm{V}_{2} \mathrm{O}_{5}$ were allowed to relax during the execution of the quantum chemical calculations. All of the atoms below the surface were kept frozen in their crystallographic positions. This was done in order to mimic the effect of the underlying layers of vanadia in $\mathrm{V}_{2} \mathrm{O}_{5}$.

The linear combination of the Gaussian-type orbital-model core potential-density functional theory (LCGTO-MCP-DFT) method, ${ }^{28-31}$ and its corresponding deMon ${ }^{31}$ package was used. The Becke 1988 exchange functional ${ }^{32}$ and the Perdew and Wang gradient-corrected correlation functional ${ }^{33}$ (BPW91) were used in this study. All the core and valence electrons were explicitly taken into account. The one-electron (orbital) basis set used in the calculations was optimized for LCGTO-MCPDFT by Godbout et al. ${ }^{34}$ In our case, the $\mathrm{V}$ and $\mathrm{H}$ basis sets are of double- $\zeta$ plus polarization quality, and triple- $\zeta$ plus polarization quality for $\mathrm{C}$ and $\mathrm{O}$, the contraction patterns being $\mathrm{V}(63321 /$ 531/41), $\mathrm{H}(41 / 1), \mathrm{C}(5211 / 411 / 1)$, and $\mathrm{O}(5211 / 411 / 1)$. The basis sets required by the LCGTO-DFT model to fit the electron density and the exchange-correlation potential have been chosen as $\mathrm{V}(5,5 ; 5,5), \mathrm{H}(5,1 ; 5,1), \mathrm{C}(5,2 ; 5,2)$, and $\mathrm{O}(5,2 ; 5,2)$. The method of partial retention of diatomic differential overlap (PRDDO/ $\mathrm{M} / \mathrm{FCP})^{35}$ was used to reduce significantly the computational cost of the potential energy sampling. PRDDO/M/FCP calculations exhibit good agreement with ab initio calculations with the same basis set although weak bonds are not described accurately. ${ }^{35}$ Such calculations are often useful for a basic understanding of structure, substituent effects, and charge distributions in a variety of molecules and to screen possible reaction pathways.

It has been shown that there is a link between the sensitivity of the chemical system to reaction and the perturbation in the electronic density of the system. ${ }^{22,36}$ The chemical perturbation is based on a DF linear response formalism. ${ }^{36}$ Since the KohnSham orbitals ${ }^{21}$ give the total ground-state electron density of the system, they also provide a measure of both the global and local chemical reactivity of the system. ${ }^{22,27,37-42}$ The Fukui functions (FF) and related hardness/softness characteristics constitute the major chemical descriptors of molecular species for open systems, in which the number of electrons is a continuous equilibrium variable. ${ }^{22}$ In the frozen core approximation the FF represent the density of the relevant frontier molecular orbital involved in electron receiving (nucleophilic attack) or withdrawing (electrophilic attack) processes. ${ }^{22,36}$ Thus, the local and the condensed FF provide information on both local reactivity and the hypothetical path by which a reactant interacts with a substrate. The reactive site within a molecule may be identified from the condensed Fukui functions and the reaction path from the Fukui function isosurfaces. We used the algorithm described by Gilardoni et al. ${ }^{43}$ to calculate the reactivity indexes. The values of the condensed Fukui function, $f_{\mathrm{k}}$, calculated for a molecular cluster representing the basal surface of $\mathrm{V}_{2} \mathrm{O}_{5}$, were derived from a numerical integration scheme that provides reliable results almost independent of the computational conditions. ${ }^{43}$

Vibrational analyses were carried out analytically on the optimized structures of the intermediate formed following the abstraction of a hydrogen atom from propane derived from calculations using the Gaussian-94/DFT program package. ${ }^{44}$ The 6-31G** (for $\mathrm{H}, \mathrm{C}, \mathrm{O}$ ) and 6-311G** (for V) basis sets were used for these calculations. Each peak of the simulated IR spectra has been assumed to exhibit the shape of a Lorentzian curve in which the width at half-height is $4 \mathrm{~cm}^{-1}$.

Rate constants were calculated directly from density functional data using the TheRate (Theoretical Rates) package. ${ }^{45}$ It allows thermal and vibrational-state selected rate constants of unimolecular and bimolecular reactions to be calculated directly from an ab initio and/or DF electronic structure theory. Geometries, gradients, Hessian matrixes, and energies calculated at the DF-GGA level (see above), were used for the reactants, products, and transition states.

\section{Results and Discussion}

Condensed FF, $f_{\mathrm{k}}$, were calculated for a molecular $\mathrm{V}_{6} \mathrm{O}_{20}$ cluster used to represent the basal plane of $\mathrm{V}_{2} \mathrm{O}_{5}$. Calculations reveal that the apical $(\mathrm{V}=\mathrm{O})$ oxygens are expected to be the most likely centers for attack by an $\mathrm{H}$ atom of propane, followed by the bridged oxygen and the 3 -fold coordinated oxygen. The values of $f_{\mathrm{k}}$ are the following: 0.30 au for the terminal apical oxygen in $\mathrm{V}=\mathrm{O}, \mathrm{O}(1), 0.02$ au for the oxygen bridging two vanadium centers, $\mathrm{O}(2)$, and 0.01 au for the bridging oxygen coordinated to three vanadium centers, $\mathrm{O}(3)$. The vanadyl oxygen is the most nucleophilic (hardest), followed by $\mathrm{O}(2)$ and $\mathrm{O}(3)$, respectively. This points out both the structural inequivalence and the differences in the local electronic environment of each $\mathrm{O}$ atom. The singly coordinated oxygen atom has an accessible and highly reactive lone pair that is available for an incoming reactant, while higher coordinated oxygens, $\mathrm{O}(2)$ and $\mathrm{O}(3)$, share their density with two or three $\mathrm{V}$ atoms. Because $\mathrm{O}(3)$ has less localized bonds, we can expect it to be more sensitive to an external perturbation, such as a protonation.

Figures $1 \mathrm{a}$ and $1 \mathrm{~b}$ show a view of the $\mathrm{V}_{6} \mathrm{O}_{20}$ cluster and an illustration of the intensity of the FF projected on a Connolly surface. ${ }^{46}$ This projection displays the position and the intrinsic chemical reactivity of a set of orbitals accessible by a reactant. ${ }^{43}$ Dark blue areas are strongly nucleophilic. Regions with high nucleophilic character can be seen for $\mathrm{O}(2)$ and $\mathrm{O}(3)$ in Figure $1 \mathrm{~b}$, but not those for $\mathrm{O}(1)$. The reason for this is that the highly nucleophilic regions for $\mathrm{O}(1)$ are situated beneath the spherically shaped lobes for these atoms on the Connolly surface. The associated orbitals point along the (010) surface and are accessible only from positions between two neighboring vanadyl groups. While the nucleophilic character of $\mathrm{O}(2)$ is greater that that of $\mathrm{O}(3)$, Figure $1 \mathrm{~b}$ shows larger projected FF values for $\mathrm{O}(3)$. This apparent contradiction is related to differences in the orientation of the orbitals of $\mathrm{O}(2)$ and $\mathrm{O}(3)$. The lone pairs of $\mathrm{O}(2)$ are pointing into the (010) surface of $\mathrm{V}_{2} \mathrm{O}_{5}$ and have an unfavorable orientation for interaction with an adsorbate as compared with the lone pairs of $\mathrm{O}(3)$, which point out of the (010) plane and are favorably oriented for interaction with an adsorbate. This demonstrates that both the FF and the condensed FF must be considered to achieve a proper description and understanding of the chemical reactivity of a system. ${ }^{22,43}$ 
(a)

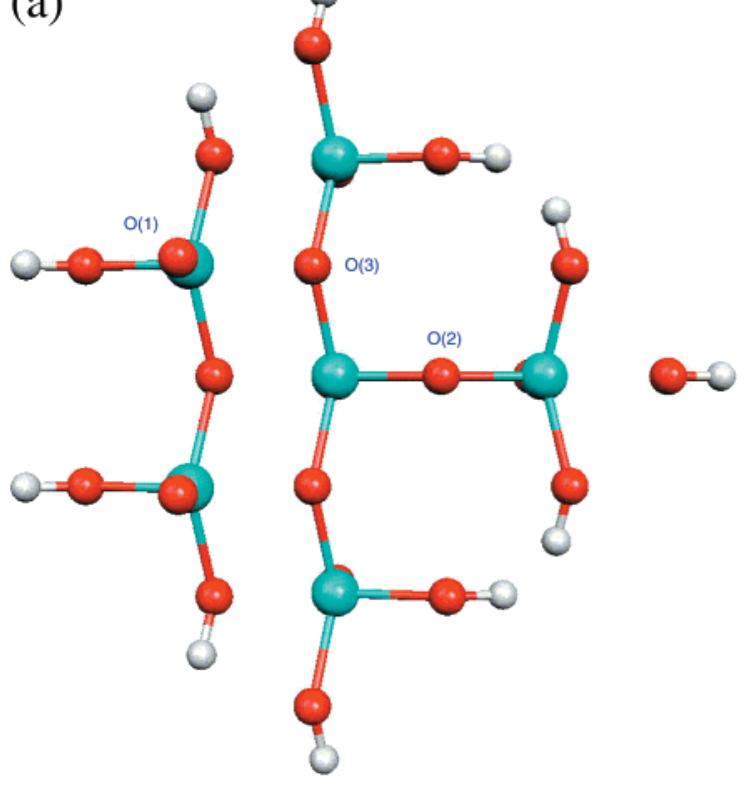

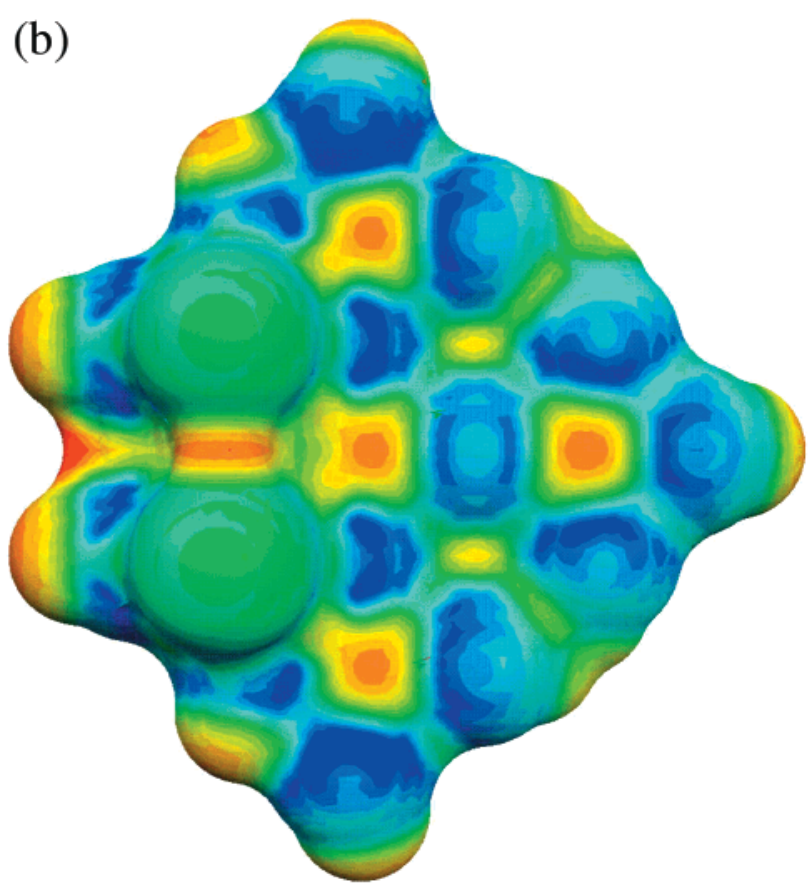

Figure 1. (a) The $\mathrm{V}_{4} \mathrm{O}_{14}$ cluster viewed looking down on the (010) surface of $\mathrm{V}_{2} \mathrm{O}_{5}$. (b) The intensity of the FF for nucleophilic attack projected on a Connolly surface for the (010) surface of $\mathrm{V}_{2} \mathrm{O}_{5}$. Dark blue regions exhibit strong nucleophic character.

Figures $2 \mathrm{a}$ and $2 \mathrm{~b}$ illustrate the reaction path for the dissociative adsorption of propane to form either $n$-propoxide or $i$-propoxide, and hydroxyl species. Since $\mathrm{O}(1)$ was found to be the most susceptible $\mathrm{O}$ atom for nucleophilic attack, $\mathrm{O}(2)$ and $\mathrm{O}(3)$ were not considered as candidates for the first step. From a formal point of view, an $\mathrm{H}$ atom can be abstracted either from a primary or secondary $\mathrm{C}$ atom leading to either $n$ propoxide or $i$-propoxide species. We first attempted to adsorb propane nondissociatively on two adjacent $\mathrm{V}=\mathrm{O}$ moieties simultaneously to form either $\left[(\mathrm{V}=\mathrm{O})_{2} \mathrm{CH}_{3} \mathrm{CH}_{2} \mathrm{CH}_{3}\right]$ or $\left[(\mathrm{V}=\mathrm{O})_{2^{-}}\right.$ $\mathrm{CH}_{2}\left(\mathrm{CH}_{3}\right)_{2}$ ] entities; these calculations did not show any evidence for adsorption. We next considered electrophilic attack of propane by $\mathrm{O}(1)$ to form either $i$-propoxide or $n$-propoxide, and hydroxyl species, as shown in Figures $2 \mathrm{a}$ and $2 \mathrm{~b}$. The sequence of structures displayed in Figures $2 a$ and $2 b$ were obtained in the following manner. On the basis of an analysis of the FF for both $\mathrm{V}_{2} \mathrm{O}_{5}$ and propane, a first possible guess was made for the structures of the transition state. To define the reaction path, a linear combination of normal modes was taken corresponding to the transfer of a proton from a $\mathrm{C}-\mathrm{H}$ bond in propane to an $\mathrm{O}$ atom in the catalyst cluster. Starting from this initial state, the DF program was used to optimize the structure for the transition state and to relax it to the product state. Exploration of the reaction pathway suggests that two $\mathrm{V}=\mathrm{O}$ groups connected by a $\mathrm{V}-\mathrm{O}-\mathrm{V}$ bridge are required for the initial activation of propane. Notice that the initial interaction of $\mathrm{C}_{3} \mathrm{H}_{8}$ with a $\mathrm{V}=\mathrm{O}$ group involves simultaneous interaction of the $\mathrm{C}$ atom and one of the $\mathrm{H}$ atoms in the methylene group in $\mathrm{C}_{3} \mathrm{H}_{8}$ with the apical $\mathrm{O}$ atom. During this process, the bond length of the interacting $\mathrm{V}=\mathrm{O}$ bond is elongated by roughly $+0.30 \AA$ because of the presence of the $\mathrm{H}$ atom, which is formally positively charged. The corresponding $\mathrm{O}-\mathrm{V}-\mathrm{O}$ valence angle decreases by $9^{\circ}$. This instability becomes the driving force for the subsequent formation of a $\mathrm{C}-\mathrm{O}$ bond and the barrierless migration of an $\mathrm{H}$ atom to a second $\mathrm{O}$ atom associated with a $\mathrm{V}=\mathrm{O}$ group. The energy of reaction of propane to form $n$ - and $i$-propoxide species at $0 \mathrm{~K}$ are $\Delta E=-28.4$ $\mathrm{kcal} /$ and $\Delta \mathrm{E}=-36.4 \mathrm{kcal} / \mathrm{mol}$, respectively. The associated activation energies are $E_{\mathrm{a}}=14.5 \mathrm{kcal} / \mathrm{mol}$ (frequency $=1119 \mathrm{i}$ $\mathrm{cm}^{-1}$ ) for $n$-propoxide and $E_{\mathrm{a}}=9.4 \mathrm{kcal} / \mathrm{mol}$ (frequency $=$ $1276 \mathrm{i} \mathrm{cm}^{-1}$ ) for $i$-propoxide.

The harmonic vibrational frequencies were calculated analytically for both the transition state and the product states shown in Figures $2 \mathrm{a}$ and $2 \mathrm{~b}$. Figures $3 \mathrm{a}-\mathrm{c}$ show the simulated infrared spectra for $n$-propoxide and $i$-propoxide species, respectively. The spectra in Figure 3 can be divided into three principal regions. The first one $\left(100-1600 \mathrm{~cm}^{-1}\right)$ contains contributions from the catalyst, and the bending and rocking modes associated with the alkoxides. The pattern looks different for $n$-propoxide and $i$-propoxide. The spectra of $n$-propoxide shows that this first region contains a rich structure of peaks with similar intensities. In the case of $i$-propoxide, the spectra reveal three distinct families of peaks with strong intensities. Although the spectra of $n$ - and $i$-propoxide do not match in this first region, it would be difficult to distinguish the two species experimentally if they would exist simultaneously in the reactor. The second region $\left(2700-3100 \mathrm{~cm}^{-1}\right)$ contains the $\mathrm{C}-\mathrm{H}$ stretching modes, but in this case, the two species can be easily discriminated. However, assuming the simultaneous adsorption of both species on the catalyst, only the peak at $2841 \mathrm{~cm}^{-1}$ ( $n$-propoxide, stretching $\mathrm{CH}$ in $\left.\mathrm{O}-\mathrm{CH}_{2}\right)$ and the peak at $3050 \mathrm{~cm}^{-1}$ ( $i$-propoxide, stretching $\mathrm{CH}$ in $\mathrm{CH}_{3}$ ) would allow a clear differentiation between the two species. The third region contains only one peak at $\sim 3100 \mathrm{~cm}^{-1}$, which corresponds to the $\mathrm{OH}$ stretching mode.

We next investigated the abstraction of an $\mathrm{H}$ atom of the $i$-propoxide species by surface or lattice oxygen. $\mathrm{O}(1,2,3)$ were all considered as candidates for this second hydrogen abstraction, although $\mathrm{O}(2)$ could be excluded, a priori, because $\mathrm{O}(2)$ has lone pairs that are unfavorably oriented for interaction with an adsorbate. We sampled the potential energy surface (PES) of the $i$-propoxide-O $(1,2,3)$ systems by using the PRDDO package after we had tested its reliability against DF calculations. No $\mathrm{H}$ abstraction was observed in any case. The weaker than anticipated nucleophilic character of $\mathrm{O}(1)$ is surprising and may be a consequence of the partial transfer of electron density from 
a

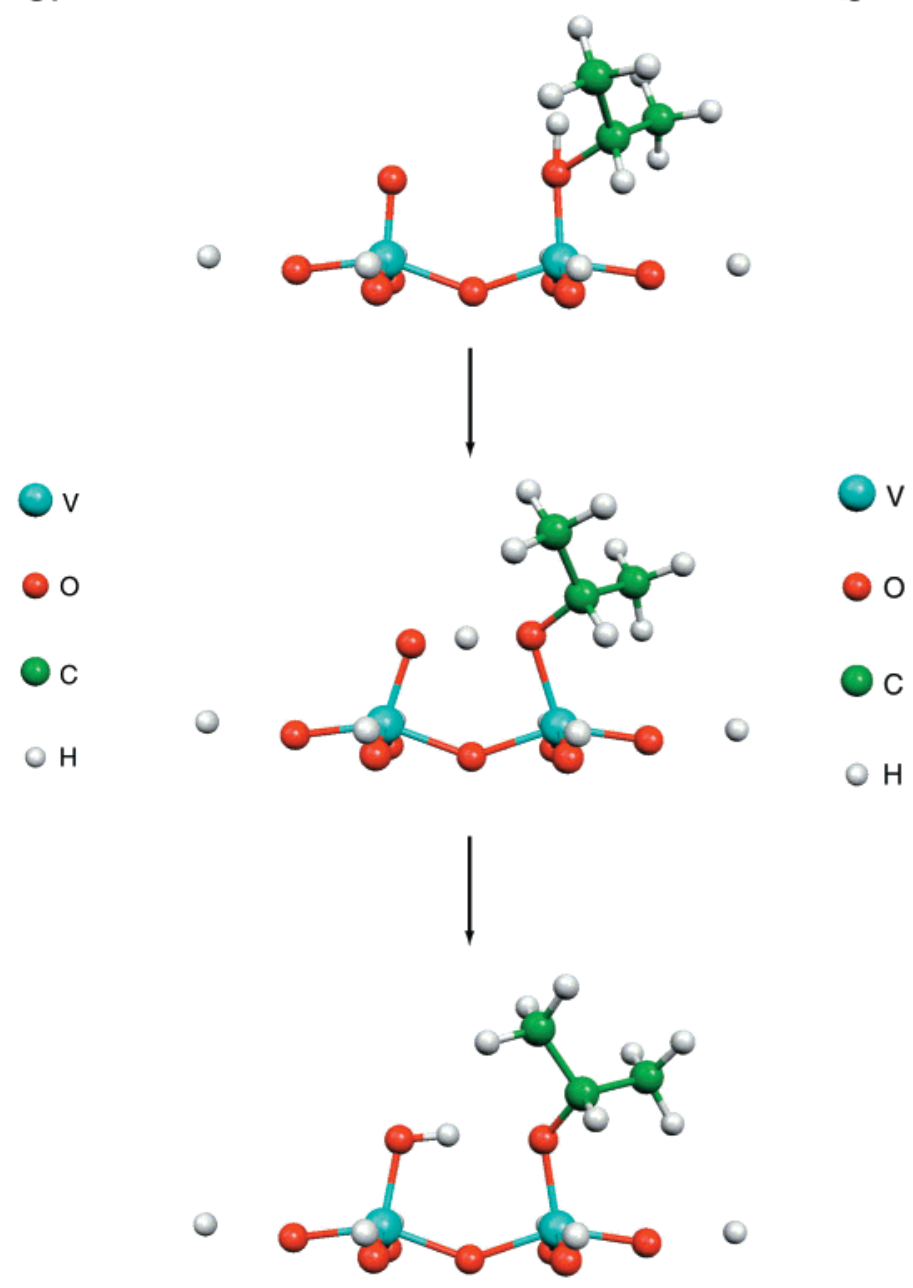

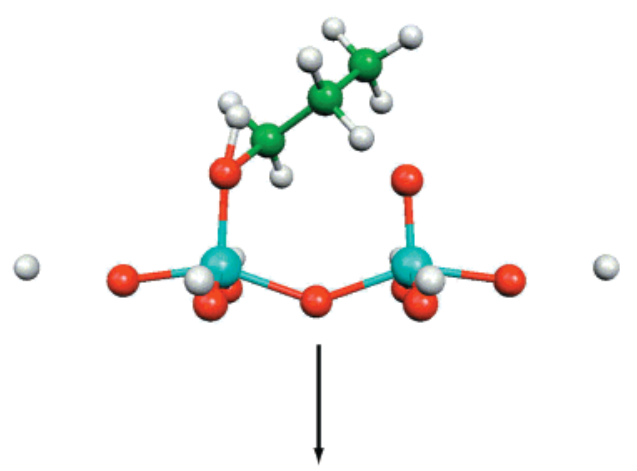

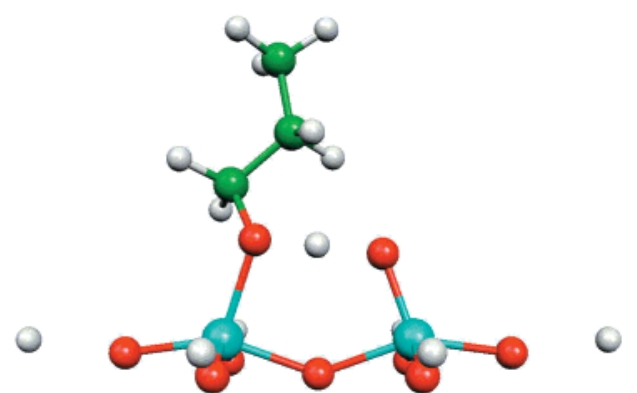

$\odot$

Figure 2. (a) Illustrations of the reactant, transition, and product states involved in the removal of a hydrogen atom from propane to form $i$-propoxide species. (b) Illustrations of the reactant, transition, and product states involved in the removal of a hydrogen atom from propane to form $n$-propoxide species.

the $\mathrm{V}^{5+}$ cation, to which the $\mathrm{O}(1)$ atom is bonded, to the $\mathrm{V}^{4+}$ cation to which the $i$-propoxide is bonded. Moreover, we were unable to find a conformation for the $i$-propoxide structure that simultaneously aligned the $\mathrm{p}_{z}$ orbitals on the $\mathrm{C}_{\alpha}$ and $\mathrm{C}_{\beta}$ carbon atoms so as to enable formation of a $\pi$ orbital in propene and the overlap of a $1 \mathrm{~s}(\mathrm{H})$ orbital in a methyl group, and a $2 \mathrm{p}(\mathrm{O})$ orbital in the cluster.

Quantum calculations ${ }^{18,47}$ indicate that proton migration from one $\mathrm{O}$ atom to another on the (010) surface of $\mathrm{V}_{2} \mathrm{O}_{5}$ should occur with only a small activation barrier. As a consequence, we investigated the influence of an $\mathrm{H}$ atom interacting with $\mathrm{O}(1)$, $\mathrm{O}(2)$, and $\mathrm{O}(3)$, respectively. Our calculations confirmed that hydrogen can adsorb at any of the three different surface oxygen sites. The $\mathrm{OH}$ groups formed at the $\mathrm{O}(3)$ site relaxes outward by an appreciable amount $(0.35 \AA)$ affecting the geometry of the $(010) \mathrm{V}_{2} \mathrm{O}_{5}$ surface. As the $\mathrm{V}-\mathrm{O}(3)$ bond is weakened due to the interaction with the $\mathrm{H}$ atom, the resulting $\mathrm{O}(3) \mathrm{H}$ group becomes highly reactive. The hydroxyl group may then combine with another hydrogen abstracted from the alkoxide to form water, which may desorb. Our calculations show, therefore, that $i$-propoxide is not oxidized by a surface $\mathrm{V}=\mathrm{O}$ oxygen atom, but by a protonated 3-fold coordinated lattice oxygen. As done previously, we sampled the reactivity of hydroxyl groups formed from $\mathrm{O}(1,2,3)$. Protonated $\mathrm{O}(1,2)$ were not able to abstract an
$\mathrm{H}$ atom from $i$-propoxide. This result is not surprising considering that the $\mathrm{O}(1) \mathrm{H}$ is strongly bound to a $\mathrm{V}$ atom and $\mathrm{O}(2)$ has both an unfavorable orbital configuration for reaction and is sterically hindered. The sampling of the potential energy surface indicates that the $\mathrm{H}-\mathrm{O}(3)$ species abstracts an $\mathrm{H}$ atom from a methyl group atom of $i$-propoxide. Propene and water are released and a vacancy is created in the catalyst. Figure 4 shows snapshots of the reaction pathway. The energy of reaction for the second $\mathrm{H}$ abstraction is $-36.5 \mathrm{kcal} / \mathrm{mol}$, not taking into account the reconstruction of the catalyst. Because of the size of the cluster and the large number of degrees of freedom, the transition state could not be identified definitively. However, by an extensive sampling of the PES around the assumed transition state, its energy could be estimated. The fitting of the energy profile leads to a transition-state energy of about 15 $\pm 2 \mathrm{kcal} / \mathrm{mol}$.

The results of the present study support the mechanism of propane ODH over vanadia proposed by Chen et al. ${ }^{8,11}$ and provide additional insights into the elementary processes involved. The mechanism of Chen et al. envisions the reversible adsorption of propane on the surface of vanadia and subsequent reaction with two oxygen atoms to form propoxide and hydroxyl species. Isotopic labeling experiments indicate that the second step is irreversible. The propoxide species then react with an 

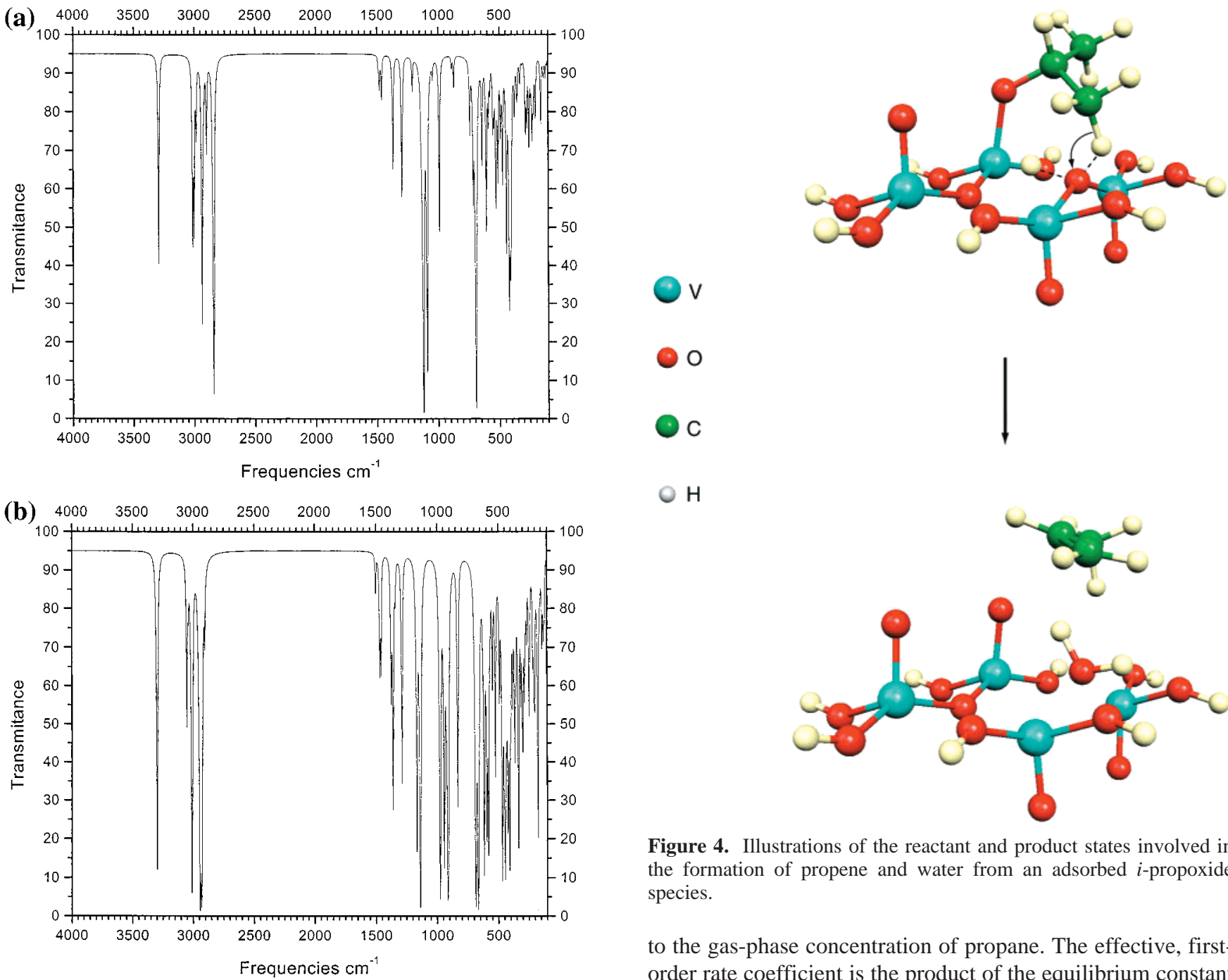

$\mathrm{H}$

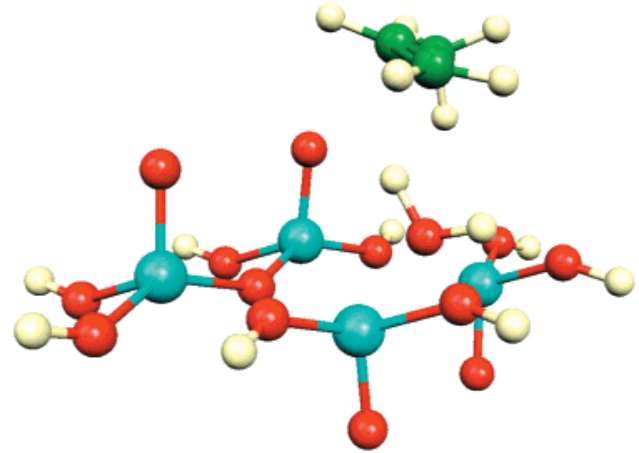

Figure 4. Illustrations of the reactant and product states involved in the formation of propene and water from an adsorbed $i$-propoxide species.

to the gas-phase concentration of propane. The effective, firstorder rate coefficient is the product of the equilibrium constant for propane adsorption and the rate coefficient for the abstraction of a hydrogen atom from adsorbed propane. Alternatively, one can view the effective rate coefficient as that for the irreversible, dissociative adsorption of propane. The rate expression derived from the proposed mechanism successfully describes the kinetics of propane ODH for both dispersed and bulk vanadia.

The assumption that two oxygen-containing sites on the catalyst are required for the dissociative adsorption of propane is well supported by the calculations presented here. However, no evidence is found for the assumption that propane must first adsorb molecularly before undergoing dissociative adsorption. ${ }^{8,11}$ Comparison of the energetics for propane dissociation to form $i$-propoxide species with those to form $n$-propoxide species indicates that the former is preferred; the activation barrier to form $i$-propoxide species is $9.4 \mathrm{kcal} / \mathrm{mol}$ versus $14.5 \mathrm{kcal} / \mathrm{mol}$ to form $n$-propoxide. This is in complete agreement with the results of isotopic labeling experiments, which show no kinetic isotope effect (KIE) for $\mathrm{CH}_{3} \mathrm{D}_{2} \mathrm{CH}_{3}$ versus $\mathrm{CD}_{3} \mathrm{CD}_{2} \mathrm{CD}_{3}$, but a $\mathrm{KIE}$ of 2.7 for $\mathrm{CH}_{3} \mathrm{CH}_{2} \mathrm{CH}_{3}$ versus $\mathrm{CH}_{3} \mathrm{CD}_{2} \mathrm{CH}_{3}$ and a $\mathrm{KIE}$ of 2.8 for $\mathrm{CH}_{3} \mathrm{CH}_{2} \mathrm{CH}_{3}$ versus $\mathrm{CD}_{3} \mathrm{CD}_{2} \mathrm{CD}_{3} .{ }^{8}$ The calculated rate for the dissociative adsorption of propane to form an $i$-propoxide group is $3.2 \times 10^{-21} \mathrm{~cm}^{3}$ molecule $\mathrm{e}^{-1} \mathrm{~V}^{-1} \mathrm{~s}^{-1}$ at $600 \mathrm{~K}$, which is in remarkably close agreement with the value of $1.3 \times 10^{-21}$ $\mathrm{cm}^{3} /$ molecule ${ }^{-1} \mathrm{~V}^{-1} \mathrm{~s}^{-1}$ measured experimentally. ${ }^{8} \mathrm{We}$ do note, however, that while the calculated activation barrier process is $9.4 \mathrm{kcal} / \mathrm{mol}$, that measured is $24 \mathrm{kcal} / \mathrm{mol}$. This difference cannot be reconciled at present, given the lack of knowledge about the morphology and surface structure of supported $\mathrm{V}_{2} \mathrm{O}_{5}$ 
particles. Of further note is that the predicted ratio of rate for the formation of $i$-propoxide versus $n$-propoxide groups is 16 at $600 \mathrm{~K}$; however, this ratio will fall with increasing temperature because the activation barrier to form $n$-propoxide groups is higher than that to form $i$-propoxide groups. This trend with increasing temperature has recently been observed experimentally. ${ }^{48}$

\section{Conclusions}

The results presented here demonstrate that the combination of density functional theory and hardness/softness arguments can be used to gain insights into energetics and reaction pathways of elementary processes occurring during the oxidative dehydrogenation of propane. Our calculations show that two $\mathrm{V}=\mathrm{O}$ groups connected by a $\mathrm{V}-\mathrm{O}-\mathrm{V}$ bridge are required for the initial activation of propane. The Fukui function analysis reveals that the vanadyl oxygen $\mathrm{O}(1)$ is the most nucleophilic, followed by the 2-fold, $\mathrm{O}(2)$, and 3-fold $\mathrm{O}(3)$ coordinated oxygen atoms, respectively. The initial interaction of $\mathrm{C}_{3} \mathrm{H}_{8}$ with a $\mathrm{V}=\mathrm{O}$ group involves simultaneous interaction of the $\mathrm{C}$ atom and one of the $\mathrm{H}$ atoms in the methylene group in $\mathrm{C}_{3} \mathrm{H}_{8}$ with the apical $\mathrm{O}$ atom. This is followed by the concerted formation of a $\mathrm{C}-\mathrm{O}$ bond and the barrierless migration of an $\mathrm{H}$ atom to a second $\mathrm{O}$ atom associated with a $\mathrm{V}=\mathrm{O}$ group. The calculated energetics shows that the formation of $i$-propoxide species is thermodynamically $\left(\Delta E^{i-\text { prop }}=-36.4 \mathrm{kcal} / \mathrm{mol}\right.$ and $\Delta E^{n-\text { prop }}$ $=-28.4 \mathrm{kcal} / \mathrm{mol})$ and kinetically $\left(\mathrm{k}^{i-\text { prop }} / \mathrm{k}^{n-\text { prop }} \approx 16\right.$ at 600 $\mathrm{K})$ preferred. Our investigations indicate that an $\mathrm{H}$ atom can interact with either $\mathrm{O}(1), \mathrm{O}(2)$, or $\mathrm{O}(3)$ to form stable surface $\mathrm{OH}$ groups, and can affect. the geometry of the (010) surface of $\mathrm{V}_{2} \mathrm{O}_{5}$ and its reactivity. Abstraction of an $\mathrm{H}$ atom from the methyl group of $i$-propoxide species is made by $\mathrm{O}(3) \mathrm{H}$ groups. These hydroxyl groups are much more reactive than either $\mathrm{O}(1) \mathrm{H}$ or $\mathrm{O}(2) \mathrm{H}$ groups. It is notable that $i$-propoxide species are not oxidized by surface $\mathrm{V}=\mathrm{O}$ oxygen atoms $[\mathrm{O}(1)]$ or 2 -fold coordinated oxygen atoms $[\mathrm{O}(2)]$. The transfer of an $\mathrm{H}$ atom from a methyl group to the bridging $\mathrm{OH}$ and the simultaneous release of water and propene is a concerted process. The energy of reaction for the second $\mathrm{H}$ abstraction is $-36.5 \mathrm{kcal} / \mathrm{mol}$, not taking into account the reconstruction of the catalyst, and the estimated activation barrier is $15 \mathrm{kcal} / \mathrm{mol}$. The principal results of the present study are in agreement with recent experiments. ${ }^{5,8,11}$

Acknowledgment. The authors are grateful to Kaidong Chen for fruitful discussions. Financial support by the Swiss National Science Foundation is gratefully acknowledged. This work was supported by the Director, Office of Basic Energy Sciences, Chemical Sciences Division of the U.S. Department of Energy under Contract DE-AC03-76SF00098.

\section{References and Notes}

(1) Blasko, T.; Lopez Nieto, J. M. Appl. Catal. A 1997, 157, 117.

(2) Kung, H. H. Adv. Catal. 1994, 40, 1.

(3) Albonetti, S.; Cavani, F.; Trifiro, F. Catal. Rev.-Sci. Eng. 1996 38,413 .

(4) Khodakov, A.; Olthof, B.; Bell, A. T.; Iglesia, E. J. Catal. 1999, 181, 205.

(5) Khodakov, A.; Yang, J.; Su, S.; Iglesia, E.; Bell, A. T. J. Catal. 1998, $177,343$.

(6) Centi, G.; Triffiro, F. Appl. Catal. A 1996, 143, 3.
(7) Mamedov, E. A.; Cortes-Corberan, V. Appl. Catal. A 1995, 127. (8) Chen, K. D.; Khodakov, A.; Yang, J.; Iglesia, E. J. Catal. 1999, $186,325$.

(9) Andersen, P. J.; Kung, H. H. J. Phys. Chem. 1992, 96, 318.

(10) Burch, R.; Swarnakar, R. Appl. Catal. 1991, 70, 129.

(11) Chen, K.; Iglesia, E.; Bell, A. T. J. Catal., in press.

(12) Oyama, S. T. J. Catal. 1991, 128, 210.

(13) Eon, J. G.; Olier, R.; Volta, J. C. J. Catal. 1994, 145, 318.

(14) Ramirez, R.; Casal, B.; Utrera, L.; Ruiz-Hitzky, E. J. Phys. Chem. 1990, 94, 8960

(15) Witko, M.; Hermann, K. J. Mol. Catal. 1993, 81, 179.

(16) Witko, M.; Hermann, K.; Tokarz, R. J. Electron Spectrosc. Relat. Phenom. 1994, 69, 89.

(17) Hermann, K.; Michalak, A.; Witko, M. Catal. Today 1996, 32, 321.

(18) Witko, M.; Hermann, K.; Tokraz, R. Catal. Today 1998, 50, 553. (19) Hermann, K.; Witko, M.; Druzinc, R.; Tokraz, R. Topics Catal. 2000, 11/12, 67.

(20) Hohenberg, P.; Kohn, W. Phys. Rev. 1964, A136, 864.

(21) Kohn, W.; Sham, L. J. Phys. Rev. 1965, A140, 1133, 57.

(22) Chermette, H. J. Comput. Chem. 1999, 20, 129.

(23) Witko, M.; Tokarz, R.; Haber, J. J. Mol. Catal. 1991, 66, 205.

(24) Hermann, K.; Bagus, P. S. Phys. Rev. 1978, B17, 4082.

(25) Petelenz, P.; Broclawik, E. J. Mol. Catal. 1991, 68, 223; Ibid. 1993 80,341 .

(26) Nalewajjski, R. F. J. Mol. Catal. 1993, 82, 371.

(27) Gilardoni, F.; Baiker, A.; Weber, J. J. Phys. Chem. A 1997, 101, 6069.

(28) Andzelm, J.; Radzio, E.; Salahub, D. R. J. Chem. Phys. 1985, 83, 4573.

(29) Salahub, D. R. Applied Quantum Chemistry; Smith, V. H., Schafer, H. F., Morokuma, K., Eds.; Reidel: Dordrecht, 1986; p 185.

(30) Salahub, D. R. Adv. Chem. Phys. 1987, 69, 447.

(31) Salahub, D. R.; Fournier, R.; Mlynarski, P.; Papai, I.; St-Amant, A.; Ushio, J. Density Functional Methods in Chemistry; Labanowski, K., Andzelm, J., Eds.; Springer: New York, 1991; p 77.

(32) Becke, A. D. J. Chem. Phys. 1988, 88, 2457. Becke, A. D. Phys. Rev. A. 1988, 38, 3098 .

(33) Perdew, J. P.; Wang, Y. Phys. Rev. 1992, B45, 13244.

(34) Godbout, N.; Salahub, D. R.; Andzelm, J.; Wimmer, E. Can. J. Chem. 1992, 70, 560 .

(35) Halgren, T. A.; Lipscomb, W. N. J. Chem. Phys. 1973, 58, 1569. Marynick, D. S.; Lipscomb, W. N. Proc. Natl. Acad. Sci. U.S.A. 1982, 79, 1341. Derecskei-Kovacs, A.; Marynick, D. S. Int. J. Quantum Chem. 1996, 58, 193. Derecskei-Kovacs, A.; Woon, D. E.; Marynick, D. S. Int. J. Quantum Chem. 1997, 61, 67. Derecskei-Kovacs, A.; Marynick, D. S. Int. J. Quantum Chem. 1997, 63, 1091. Marynick, D. S.; Axe, F. U.; Kirkpatrick, C. M.; Throckmorton, L. Chem. Phys. Lett. 1983, 99, 406. Marynick, D. S.; Reid, R. D. Chem. Phys. Lett. 1986, 124, 17. Throckmorton, L.; Marynick, D. S. J. Comput. Chem. 1985, 6, 652. Marynick, D. S. J. Comput. Chem. 1997, 18, 955.

(36) Parr, R. G.; Yang, W. Density-Functional Theory of Atoms and Molecules; Oxford University Press: New York, 1989.

(37) Parr, R. G.; Pearson, R. G. J. Am. Chem. Soc. 1983, 105, 7512.

(38) Parr, R. G.; Yang, W. J. Am. Chem. Soc. 1984, 106, 4049.

(39) Pearson, R. G. J. Am. Chem. Soc. 1963, 85, 3533.

(40) Mermin, N. D. Phys. Rev. 1965, 137, 1441.

(41) Harbola, M. K.; Chattaraj, P. K.; Parr, R. G. Isr. J. Chem. 1991, 31,395 .

(42) Baekelandt, B. G.; Cedillo, A.; Parr, R. G. J. Chem. Phys. 1995, 103,8548

(43) Gilardoni, F.; Weber, J.; Chermette, H.; Ward, T. R. J. Phys. Chem. A 1998, 102, 3607.

(44) Frisch, M. J.; Trucks, G. W.; Schlegel, H. B.; Gill, P. M. W.; Johnson, B. G.; Wong, M. W.; Foresman, J. B.; Robb, M. A.; Head-Gordon, M.; Replogle, E. S.; Gomperts, R.; Andres, J. L.; Raghavachari, K.; Binkley, J. S.; Gonzales, C.; Martin, R. L.; Fox, D. J.; Defrees, D. J.; Baker, J.; Stewart, J. P. P.; Pople, J. A. Gaussian 94/DFT, revision F4; Gaussian, Inc.: Pittsburgh, PA, 1995.

(45) Duncan, W. T.; Bell, R. L.; Truong, T. N. J. Comput. Chem. 1998, 19, 1039 .

(46) Connolly, M. L. Science 1983, 221, 709. Connolly, M. L. J. Appl. Crystallogr. 1983, 16, 548. Connolly, M. L. J. Mol. Graphics 1993, 11, 139.

(47) Hermann, K.; M. Witko, M.; Druzinic, R. Faraday Discuss. 1999.

(48) Chen, K.; Iglesia, E.; Bell, A. T. Unpublished results. 